\title{
BIOCHEMICAL DISTURBANCES IN EARLY LIFE
}

\author{
By R. H. Wilkinson, M.D. \\ Department of Chemical Pathology, The Hospital for Sick Children, Great Ormond Street, London
}

Biochemical changes occur in a wide range of diseases in paediatric practice. It is amazing what tremendous deviations from normality are compatible with life. This section will be confined to the use of chemical aids in the differential diagnosis of a difficult problem in infancy, that of failure to thrive. The differential diagnosis ranges from maternal mismanagement to galactosaemia.

Causes of failure to thrive in early life are:

I. Nutritional, e.g. feeding technique and inadequate quantity or quality of food.

2. Infective, e.g. gastro-enteritis, miliary tuberculosis and otitis media.

3. Anatomical abnormalities, e.g. hiatus hernia, obliteration of bile ducts and urethral obstruction.

4. General diseases. (a) Fibrocystic disease of pancreas; (b) Diseases listed because of biochemical interest, e.g. infantile renal acidosis, hypercalcaemia, diabetes insipidus renalis, generalized aminoaciduria and cystinosis in infants, galactosaemia and sucrosuria.

Groups I to 4 (a) need not concern us here. Group 4 (b) lists some causes of failure to thrive which require chemical investigation for their differentiation, as the clinical picture is not characteristic.

The picture of failure to thrive has common features: No gain in weight, very difficult feeding due to anorexia with vomiting and constipation. The vomiting and lack of fluid produces dehydration and this contributes to the constipation. In some cases with renal dysfunction, thirst and polyuria are present also. Fever may accompany the dehydration. Renal, cardiac, hepatic and respiratory failure, intercurrent infection or progressive biochemical abnormalities may be the outcome.

Infantile Renal Acidosis (Lightwood, Payne and Black, r953)

From about the fourth month a seemingly healthy infant commences to vomit and refuses food. The child becomes constipated, ceases to gain weight and is miserable. These symptoms continue with periods of remission until dehydraos tion becomes marked. When examined, the chil\& shows no characteristic clinical features. The weight is below normal. The child is listless, muscle tone is poor and the signs of dehydratiofy are seen. Radiography may show medullary renaN calcification. A specimen of urine may containg some protein, white cells and pathogenic organg isms, but not enough to suggest a severe urinary infection. The reaction of the urine may be acid if the child is dehydrated, but after this has beef corrected the urine is alkaline or neutral. The key to the diagnosis is the finding of a plasma bigro bonate less than $18 \mathrm{~m} . \mathrm{Eq} . / \mathrm{l}$. together with oan alkaline or neutral urine. It is good practice repeat these initial findings two or three days la after the patient has been further hydrated. Soms apparently normal children when dehydrated hav an initially low plasma bicarbonate with a neutral urine. This reverts to normal after rehydration If the findings of acidosis and neutral or alkaling urine persist (even after any urinary infection has been cured), the diagnosis is that of infantile rena acidosis.

The treatment of the condition is oral rehydra tion and sufficient alkalizing salts to correct the acidosis, such as a modified Shohl's solution (10. per cent. sodium citrate and 6 per cent. citric acis I ml. $\equiv$ I m.Eq.) sodium citrate, sodium lactate and sodium acetate (the latter tastes the least saltys Sodium bicarbonate may be used but often causes tympanites. Most cases require $15 \mathrm{~m} . \mathrm{Eq}$. q.d. This dose may be increased by $15 \mathrm{~m}$.Eq. a da each week, until the plasma bicarbonate rises $20 \mathrm{~m} . \mathrm{Eq} . / \mathrm{l}$. The clinical picture becomes strilf ingly normal and this symptomatic treatment continued until the weight gain has been saties factory for several months. The plasma bicaf bonate tends to rise above $25 \mathrm{~m}$.Eq./l. when re covery occurs. The dosage of alkali is halves, and if no acidosis appears after a fortnight, the dose is halved again. If no acidosis recurs the alkali treatment is stopped. The urinalysis shou be normal. The prognosis is excellent. 
Idiopathic Hypercalcaemia in Infants (Lightwood, 1952; Payne, 1952)

This condition resembles infantile renal acidosis clinically. The symptoms of failure to thrive are present, sometimes with thirst and polyuria. The child is often dehydrated but is cheerful and has a good skin colour, which is a point of clinical differentiation from renal acidosis. Hypotonia and constipation with scybalae palpable in the abdomen are well-marked features. Urinalysis shows some evidence of infection but not enough to diagnose a primary urinary infection. Chemical analysis shows the diagnostic signs of: Raised serum calcium (over $11.5 \mathrm{mg}$. and usually 12 to $14 \mathrm{mg}$. per $100 \mathrm{ml}$.), raised blood urea (over $40 \mathrm{mg}$. and up to $120 \mathrm{mg}$. per $100 \mathrm{ml}$.) and a normal plasma bicarbonate. Again it is wise to repeat these readings to secure a firm diagnosis, as when possible errors are eliminated, raised calcium levels occur on admission to hospital and are normal two days later. Radiography often shows an increase in density in the renal areas and dense epiphyseal lines.

Treatment is purely symptomatic. The dehydration is corrected and adequate clear fluids are given. These are usually taken readily. A low calcium diet is given and a commercial low calcium milk powder, free from vitamin $\mathrm{D}$, can be used. Cortisone by mouth may be used to reduce the serum calcium.

The disease may last one or two years in the uncomplicated case and the prognosis is good. A complete gradation may be found from this type of case to the complicated one of hypercalcaemia, basicranial osteosclerosis and craniostenosis, cardiac murmur, hypertension, mental retardation and hypercholesterolaemia, described by Fanconi et al. (1952). Some cases also have an episode of renal acidosis and some cases of renal acidosis may have a transient hypercalcaemia. The cases of hypercalcaemia may be thought of as a simple group, a complicated group and a very small group associated with renal acidosis. The prognosis in the complicated group has not been good.

Diabetes Insipidus Renalis (Pitressin resistant diabetes insipidus)

Infants who are failing to thrive become dehydrated and all benefit by the ample fluid intake given in hospital. One group of cases however requires a fluid intake of up to $200 \mathrm{oz}$. per day. The accompanying polyuria may be missed easily when the infant is given a normal fluid intake unless the above condition is kept in mind. The description by Waring, Kajdi and Tappan (1945) of this congenital defect in water metabolism is 'onset after birth, erratic and unexplained fever, persistent constipation, vomiting in the first three months of life, polydipsia and polyuria not re-

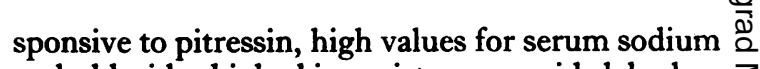
and chloride, high skin resistance, rapid dehydra- $z$ tion if fluids are restricted or withheld, inability to $\stackrel{\mathbb{Q}}{\circ}$ excrete urine of high specific gravity, familial $\stackrel{.}{.}$ incidence and occurrence in boys only.'

The clinical picture may be mistaken for gastroenteritis, a general or local infection with a pyrexia rising to $103^{\circ} \mathrm{F}$., meningitis since neck rigidity may be found, or a renal lesion as the blood urea is raised. When it is found that the child does well on large amounts of fluids and that there is a is polyuria, the case can be investigated systematic- $\overrightarrow{0}$ ally. As rehydration proceeds, the fever subsides, the high plasma chloride and sodium and blood $\vec{\omega}$ urea fall to nearly normal levels. The urine is pale $\frac{\circ}{\circ}$ and of low specific gravity (1001 to 1007). If 0 fluids are curtailed dehydration, fever, loss of weight and malaise rapidly follow in about six to twelve hours, but the specific gravity of the urine does not rise above 1007.

The critical point is the child's reaction to $\omega$ pitressin (anti-diuretic hormone, A.D.H.). He is given hourly an amount of fluid equal to the daily intake of fluid divided by 12 , starting at 6 a.m. and $\vec{c}$ continuing until 3 p.m. A catheter is inserted at 8 a.m. This procedure may inhibit urine formation for up to one and a half hours. Hourly speci ${ }^{\circ}$ mens of urine are collected from ro a.m. till midday and serve as controls. Pitressin (Par Davis) watery solution, 0.5 B.P. unit per sq. ne of body surface is injected subcutaneously at i2 midday. Hourly specimens of urine are collected till 3 p.m. The pitressin solution should have been $\stackrel{\odot}{\circ}$ tested on a normal subject and proved to be active. $\overrightarrow{\vec{P}}$ The normal reaction is a fall in the hourly volume of the urine and a rise in the concentration of $\square$ chlorides, although the amount of salt excreted per: hour is not altered.

The child whose kidney is resistant to the antidiuretic action of the pitressin shows no reaction to $\frac{\dot{\sigma}}{2}$ the test, and the dose may be increased tenfold. 3 . The patient is much more sensitive than a normal 8 infant to the vasopressor effect of the preparation in these high doses. Since the water loss cannoto be controlled with pitressin the only treatment is to teach the parents to supply the infant with large 음 quantities of fluid while giving enough food.

Generalized Aminoaciduria and Cystinosis $N$ in Infants (Bickel et al., 1953)

Generalized aminoaciduria occurs in a group of ${ }_{\sigma}^{\omega}$ infants showing a wide range of clinical pictures and cystinosis may or may not be demonstrated. The infant fails to thrive after the age of about six months, when vomiting, anorexia, constipation, marked thirst and polyuria appear. The thirst is so marked that known cases of cystinosis are given $\frac{\overrightarrow{ }}{\stackrel{0}{0}}$ cups of water when seen as out-patients. Loss of $\frac{\pi}{0}$ 
weight is noticed. The child appears small, dehydrated, has a fever and may be cold and cyanotic. Rickets may or may not be present. Albuminuria, glycosuria and pyuria may be found. Blood chemistry shows a marked metabolic acidosis and a low inorganic phosphorus. Serum potassium may show low levels associated with fever and a raised blood urea level.

Any infant who fails to thrive, has marked thirst and passes a dilute urine containing excess protein, with or without reducing substances, should have several specimens examined for aminoaciduria and sugar excretion by paper chromatography. If a generalized aminoaciduria of a characteristic type is found, the corneae should be examined by slit-lamp microscopy for cystalline deposits and marrow smears examined for cystine crystals. The latter may be identified specifically by paper chromatography. The urine examination by paper chromatography is the critical examination. Treatment is symptomatic, potassium and alkalizing salts are given in doses sufficient to correct the plasma deficiencies. A dose of up to $30 \mathrm{~g}$. a day of sodium and potassium citrate may be necessary. High doses of vitamin D (50 to 200,000 units) may correct the rickets.

\section{Galactosaemia (Cox and Pugh, 1954)}

This disease must be diagnosed as soon as possible after birth if the infant is to be given a chance to develop normally. The infant fails to thrive from birth and the weight gain is poor. Feeding is difficult as the baby vomits, is sometimes drowsy and sometimes irritable and may have convulsions. Diarrhoea may occur. Wasting and dehydration are usual although oedema and ascites are sometimes seen. The early and important signs are those affecting the liver. It is enlarged very early in the disease, accompanied by jaundice and sometimes by splenomegaly. The older case may show, unfortunately, the fully developed picture of malnutrition, hepatomegaly, lamellar or nuclear cataracts and mental deficiency. A family history of the disease may be obtained in one-third of the cases. Benedict's reagent is strongly reduced by the urine, and albuminuria and a few cells and casts are seen.

Failure to thrive, hepatomegaly and a reducing substance in the urine of an infant should cause the clinician to suspect galactosaemia. Identification of the urinary excretion of galactose in large amounts is obtained most easily by paper chromatography of the urine passed while a diet containing lactose is fed. Aminoaciduria may also be found. The treatment of the condition is to exclude lactose from the diet and commercial dried milks are avail-气 able for this purpose. The diagnosis must be 3 made as early as possible so that the danger of $\varrho$ cataracts and mental deficiency may be minimized. $\subseteq$ It is not yet possible to form an opinion of the $\vec{F}$ mental progress in cases which have been treated early.

\section{Sucrosuria}

This rare condition again illustrates the use of $\stackrel{\mathbb{2}}{\circ}$ paper chromatographic analysis of urine. Three cases of sucrosuria with mental defect and hiatus $\vec{\circ}$ hernia were described by Moncrieff and Wilkinson (1954). The infants were all failing to thrive, $\vec{\omega}$ principally because of hiatus hernia, and were mentally deficient. Vomiting and failure to gain weight were the principal symptoms. Radiography demonstrated the lesion of the lower end $\stackrel{\omega}{-}$ of the oesophagus. It was shown that on ordinary milk feeds, containing lactose and sucrose, greatly. increased quantities of sucrose, lactose, fructose $\frac{P}{C H}$ and, to a less extent, glucose and galactose were passed in the urine. The defect appeared to be in the intestinal absorption of sugars when lactose and ${ }_{c}^{-}$ sucrose were fed together. These two disaccharides were absorbed more rapidly than usual and the sugars were promptly excreted by the kidney. The hiatus hernia was treated and the children we $e^{\mathrm{r}}$ given sucrose-free diets. The sucrosuria ceas $\overline{\mathrm{g}} \mathrm{d}$. and this possibly toxic factor was eliminated. Twos of the cases died and the third case has made slowo physical progress.

\section{Summary}

Six examples are given of the use of chemical aids in the differential diagnosis of failure to thrive? in infancy. Infantile renal acidosis and idiopathiợ hypercalcaemia require blood analysis for bicarbonate, calcium and urea. Diabetes insipidus 3 . renalis requires a test of the reaction of theo patient's kidneys to pitressin (A.D.H.). Cystinosis, galactosaemia and sucrosuria are demonstrated byô the analysis of urine by paper chromatography.

\section{BIBLIOGRAPHY}

BICKEL, H., BAAR, H. S., ASTLEY, R., DOUGLAS, A. A. $\frac{7}{O}$ FINCH, E., HARRIS, H., HARVEY, C. C., HICKMANS, EMELLIE, J. M., and TEALL, C. G. (1953), Acta paed.' 42, supp. 90.

COX, P. J. N., and PUGH, R. J. P. (1954), Brit. med. F., ii, 6ra. N FANCONI, G., GIRARDET, P., SCHLESINGER, B., BUTLER N N., and BLACK, J. (1952), Helv. paediat. acta, 7, 314. LIGH'TWOOD, R., PAYNE, W. W., and BLACK, J. A. (1953)

LIGHTWOOD, R. (1952), Arch. Dis. Childh., 27, 302.

MONCRIEFF, A. A., and WILKINSON, R. H. (1954), Acta paed. 43, supp. IOO, 495 .

PAYNE, W. W. (1952), Arch. Dis. Childh., 27, 302.

WARING, A. J., KAJDI, L., and TAPPAN, V. (1945), Amer. 7. Dis. Child., 69, 323. 